\title{
A Simple Method of Ship Dynamic Trimming Optimization
}

\author{
Qiang Zhang ${ }^{1,2, a}$, Zhaoxin Zhou ${ }^{1, b}$, Xiangxin Cheng ${ }^{1, \mathrm{c}}, \mathrm{Na}$ Jiang $^{1}$, Fanyi Kong ${ }^{1}$ \\ ${ }^{1}$ Maritime College, Shandong Jiaotong University. Weihai 264200, China; \\ ${ }^{2}$ Navigation College, Dalian Maritime University. Dalian 116071, China. \\ a zq20060054@163.com, ${ }^{\mathrm{b}}$ zhouzhaoxinwh@126.com, ${ }^{\mathrm{c}}$ 283998148@qq.com
}

Keywords: Trimming optimization; dynamic; loading computer.

\begin{abstract}
In order to cope"Guidelines for voluntary use of Energy Efficiency Operational Indicators( EEOI)", a simple method of adjusting ship trimming of a voyage has been attempted,which can minimize the energy consumption and economize cost.A method of ship dynamic trimming optimization base on loading computer is introduced by theories analysis and sea trial of real ships, which can be easily operated and obtained the value of the dynamic trimming optimization by mariners. Comparing the real ship experiment data with the value of experience, this method will be reduce by $1.1 \%$ energy consume. Meanwhile, comparing the traditional computational fluid dynamics (CFD) method,this method cost more less. This paper also provides a new research way to analyze the ship optimistic maneuvering by the big data analysis when ship-shore internet are completed economically.
\end{abstract}

\section{Introduction}

The Sea Environment Committee (MPE59) approved“Ship's Energy Effect Management plan(SEEMP)”, “Guidelines for voluntary use of Energy Efficiency Operational Indicators ( EEOI)”. So that the ship's owner and the shipping company are easily to accept the new green ship technology of the reducing glasshouse gas exhausting and the energy consumption during ship operational management.

Since 1980s, the trimming optimization had been becoming hot point of study. But owe to the technology of computer and sensor was not well developed and lack of the consciousness of economizing the energy and environmental protection at that time. There are few of the optimization trimming systems can be applied to the real ship, and the optimizing dynamic trimming systems which consider the fact of environment influence are more less. The trimming optimization can be made by means of model tests or by means of computational fluid dynamics (CFD). Some results of possible power gains proven by CFD methods have been reported by Hansen and Hochkirch[1,2].Wang Wei [3]and Qu BingBing [4]introduce the way of the optimization trimming technology by CFD, verifying the pool experiment and the real ship data, and achieved good economic result which apply to the fleet of China shipping company and China ocean shipping company (DaLian COSCO) in 2014. Minchev[5]discuss the three methods of the trim optimization technology by utilizing the experiment of ship model,which influenced by full resistance and self-propulsion,resistance for a reference trimming,direct power.

But the dynamic trimming optimization technique was usually neglect under the application of the traditional CFD and the ship mold experiment technique. The error margin that the dynamic trimming measure usually will be neglect,due to ship sailing at sea will be influenced by wind and current,which the difference between the actual angle of trimming and the static state trimming angles is large sometimes. In addition, energy consumption management plan is carried out compulsory "Each ship shall keep on board a ship specific Ship energy efficiency management plan from 1st January 2013,(2011Marpol Annex VI Amendments)”. The ship trim optimization is described in this plan,for instance "it is generally better to sail with minimum draft and slightly trimmed by the bow to the extent possible”, but the valid scope of the best trim was not fixed by the rule. And the external environment influence, including the best speed,was not considered.Therefore 
it needs the mariners to find out the best trim under certain loading condition through the actual ship experience.

Basing on the trim optimization technique and loading computer ,this paper introduce a method of dynamic trim optimization by the real ship's experience.The sea trial of one chemical tanker in light displacement condition was carried out.Comparing with mariner's experience data ,the result of sea trial show that the trimming by dynamic optimization technique will reduce by $1.1 \%$ energy consuming.Meanwhile,comparing the computational fluid dynamics (CFD) method,this method cost more less. This paper also provides a new research way to analyze the ship optimistic maneuvering by the big data analysis when ship-shore internet are completed economically.

\section{Trimming optimisation theory}

\section{The Definition of Trim}

The ship floating on static water in stable equilibrium is called the ship's float state. There are 4 states of ship which are even keel, heeling, trimming, and trimming\&heeling. The parameter of ship's $\operatorname{draft}(\mathrm{d})$, angle of heeling $(\theta)$, angle of trimming( $\phi$ )or trim(t) can represent that 4 states. The inclining direction from forwards or afterwards without any heeling and even keel is called trimming. It will creative a trim by head ( $\mathrm{t}$ ) or trim by stern $(\mathrm{t})$ and angle of trimming $(\phi)$ when ship is in trimming.

Trim is the difference between forward draft and afterward draft.(see fig.1)

$$
\mathrm{t}=d_{F}-d_{A}
$$

Angle of trimming ( $\phi$ )is the an angle between water plane of trimming and water plane of even keel. Normally trim by head is positive, trim by stern is negative. Trim(t) and angle of trimming $(\phi)$ are representing the scope of trimming.

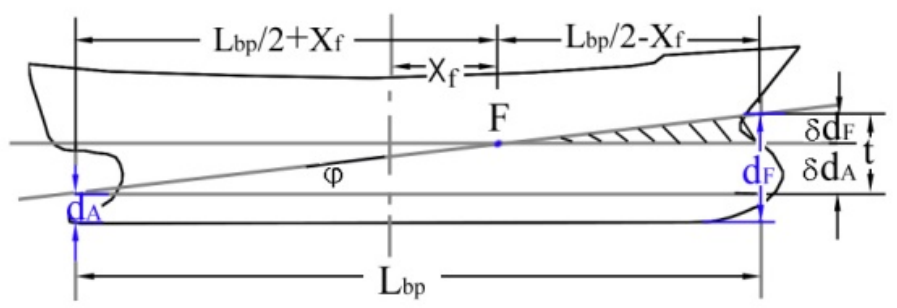

Fig.1 Trimming calculation

\section{The Definition of Dynamic Trimming Optimization}

The alteration of ship resistance is caused by the change of underwater hull of geometrical volume of ships, if the trimming state has been changed at fixed displacement. Meanwhile, because of the change of ship sailing states, the different trimming also could cause the variety of the flow's field of the ship stern, then affecting the propulsion efficiency of the ship propeller. Considering the navigation environment factors when sailing at sea,the dynamic trimming optimization can be carried out the accurate measurement at any time and acquired the better ship's speed. Therefore, it could be the dynamic trimming optimization which related data of external environment factor are measured when real ship sailing at sea.

\section{Theories Foundation}

According to the hydrodynamics analysis, ship will be effected by resistance of water and the air resistances when sailing at sea,of which the water resistance is the most influence on. Under certain displacement condition,the changing of trim angle will cause the varieties of the underwater hull of geometrical volume .Therefore the shape of water plane, the position of center of buoyancy, the current form bow and the stern current will be changed accordingly. The result could cause the varieties of water resistance when ship sailing at sea.(including the friction resistance,viscous pressure resistance). Meanwhile, the different trimming angle cause the varieties flow of stern field, which affect the propulsion efficiency of the ships propeller due to the alteration of ship sailing states. 
The study shows, excepting the influence factor of water depth, the different of line type of ship correspond with a best definite float state in different draft(ship condition with full loading, half loading, light loading), and different speed.

\section{The Trim Requirement During Ship Operation}

If trim by head, it would reduce ship's speed and cause difficult maneuvering and immerse the ship bow. When ship pitching,the propeller sometimes dip into the water and sometimes out of surface, which cause the main engine unstable working load and its affect normal working condition of main engine. If trim by stern too much, it can be difficult to maneuver the ship and steer the course,that also could damage the sole plate of the bow when hitting the sea wave and it is disadvantage to ship lookout for the mariners.

The Experienced Trim.According to traditional voyage experience, the suitable trim by stern are required, which could increase ship speed and the propulsion efficiency of the ship's propeller, and improve the rudder effectiveness when ship sailing at sea.

And the following trim consideration shall be taken into account for 10,000 dead weight tonnage ship:Full displacement $\mathrm{t}=-0.3 \mathrm{~m} \sim-0.5 \mathrm{~m}$; Half displacement $\mathrm{t}=-0.6 \mathrm{~m} \sim-0.8 \mathrm{~m}$; Light displacement $\mathrm{t}=-0.9 \mathrm{~m} \sim-1.9 \mathrm{~m}$. To avoid grounding, the full displacement of big tonnage ships are suggested to keep even keel in shallow water, it is available to get more stowage to be loaded under the limitation of draft.

The Minimum Trim Requirement.According to the IMO (International Maritime Organization) rules,Shanghai ships institute of transportation has analyzed the minimum requirement of trim by head and even keel and suggest the Chinese ocean going vessel to satisfy the following requirement:

$$
\begin{aligned}
& L_{B P}>150 \mathrm{~m},\left\{\frac{d_{F(\min )} \geq 0.012 L_{B P}+2(\mathrm{~m})}{d_{M(\min )} \geq 0.02 L_{B P}+2(\mathrm{~m})}\right. \\
& L_{B P} \leq 150 \mathrm{~m},\left\{\frac{d_{F(\min )} \geq 0.025 L_{B P}}{d_{M(\min )} \geq 0.02 L_{B P}+2(\mathrm{~m})}\right.
\end{aligned}
$$

Therefore, the suitable trim by stern are required when ship sailing at sea, and the scope of trim by stern will be taken into account by the different size of ship and different displacement state. In past shipping practice, ship's captain adjust trim according to the above-mentioned suggestion which is suitable for small type of ship to increase efficiency. However, with the development of shipping industry,the ship body line type variety obviously, especially for the high speed and very large carrier.Then the large ship maneuvering theories have gradually changed the concept of increasing speed and economize energy by using the suitable trim by stern.

\section{Trimming optimisation method}

Nowadays, the traditional method of research one type of ship is by using CFD to achieve the compounding resistance regulation of various trimming state combining with float condition.

The hydrodynamic and analysis software are adopted to analysis optimization trimming to provide the suggestion for the optimistic trim during ship actual operation.Firstly computational fluid dynamics and automatic data of imitation processing method are applied to calculate resistance of different speed and stowage of ship. And then a great deal of stimulative data are used to work out the main engine power curve by various of draft and ship speed. Finally the pool experiment or sea trial are conducted to verify the spot accuracy and work out the optimization trimming at different draft and speed by calculating software.Therefore, this stimulative method is not available for the dynamic trim optimization which are affected by voyage environment at the same time.

The effective verification method: There are two methods of verification of trimming curve which calculate by CFD using the application of 3D model,of which are pool experiment and sea trial. In view of application of equivalent scale model tested in the pool,the pool experiment can be carried out under multi-work conditions. But the result of experiment would be likely to deviate from the 
actual condition,.Meanwhile, due to the high cost, sea trial can not be obtained much more results in multi-work conditions.

However,some vessels especially the bulk carrier or oil tanker which sail with single condition of light displacement on the longtime voyage during ship commercial operation. Therefore a method of using the ballast water to adjust the optimistic trimming which can economize the pool experiment cost and reduce the deviation of the Model can be easily achieved under single condition.

\section{Trimming optimisation simple method in practice}

A simple method of utilizing the ballast water to adjust the the trim is suitable for single condition ship,especially the bulk carrier or oil tanker which sail with single condition of light displacement on the longtime voyage.First of all ,the data of fore and after draft on the voyage are measured by detector sensor which different data from the draft in static water .Secondly the ship's stability and strength are monitored by Loading computer in whole process of ballast for the safety reason, then a database is established by this way.Finally ,the dynamic optimistic trim is calculated by using the loading computer to get optimistic trim data from database directly. The sea trial was conducted by a oil/chemical of M.T. C.A.which ship's main particulars are shown as table 1.The sea trial conditions as follows.This vessel sailed near equator of Indian ocean,(GPS POSITION LAT.05 ${ }^{\circ}$ 32.3N.LONG.086 ${ }^{\circ}$ 02.4E).Fine day, calm sea, slight wind, small leeway.

Table.1 Main particulars of reference vessel

\begin{tabular}{|l|l|}
\hline Item & Particulars \\
\hline Type of ship & oil/chemical tanker \\
\hline length overall & $134.2 \mathrm{~m}$ \\
\hline Breadth moulded & $20.0 \mathrm{~m}$ \\
\hline Designed draft moulded & $7.6 \mathrm{~m}$ \\
\hline Light ship weight & $3880.789 \mathrm{t}$ \\
\hline length between perpendiculars & $126.0 \mathrm{~m}$ \\
\hline
\end{tabular}

Ballast Procedure.The experienced drafts are that forward draft $3 \mathrm{~m}$ and after draft $5 \mathrm{~m}$ with 3100 tons sea water under light displacement condition by mariners. There are 10 ballast water tanks

(1W-5W) in M.T CA of which the $1 \mathrm{~W}$ and $5 \mathrm{~W}$ of ballast water tanks are transferred to adjust the trim.Meanwhile the draft detector and GPS are available to record the dynamic draft and speed data when ship sailing at sea. The ballast schedule are shown as table 2.

Table. 2 Ballast water transfer procedure

\begin{tabular}{|l|l|l|l|l|l|l|}
\hline No. & $1 \mathrm{w}$ BWT & $5 \mathrm{w}$ BWT & \multicolumn{1}{|c|}{$\mathrm{d} \mathrm{f}$} & $\mathrm{d} \mathrm{a}$ & trimming/m & speed $/ \mathrm{kt}$ \\
\hline 1 & 1200 & 0 & 4.501 & 3.505 & 0.996 & 11.8 \\
\hline 2 & 1100 & 100 & 4.263 & 3.769 & 0.494 & 11.85 \\
\hline 3 & 1000 & 200 & 4.025 & 4.032 & -0.007 & 12 \\
\hline 4 & 900 & 300 & 3.787 & 4.295 & -0.508 & 12.22 \\
\hline 5 & 800 & 400 & 3.549 & 4.558 & -1.009 & 12.33 \\
\hline 6 & 700 & 500 & 3.311 & 4.821 & -1.51 & 12.3 \\
\hline 7 & 600 & 600 & 3.073 & 5.084 & -2.011 & 12.2 \\
\hline 8 & 400 & 800 & 2.597 & 5.61 & -3.013 & 11.92 \\
\hline 9 & 300 & 900 & 2.36 & 5.872 & -3.512 & 11.83 \\
\hline
\end{tabular}

The Monitor of Loading Computer.The ship's stability and strength data are monitored by loading computer during the whole process of ballast which are in the safety condition.The loading computer main interface and the shear force and bending moment interface are shown as figure 2.The following two figures show that all data in allowable scope.

The Sea Trial Result .Comparing the data of sea trial, the quickest speed is 12.33 Knots and optimistic trim is $-1.009 \mathrm{~m}$. The optimistic trimming state is loaded with the 3100 tons cargo or ballast water according the data of the curve. The formula is matched by 4 rank polynomial curves as formula 4,of which trim data less than -3.5 are not taken into account . 


$$
\mathrm{y}=0.023 \times x^{4}+0.12 \times x^{3}+0.0074 \times x^{2}-0.037 \times x+12
$$

Therefore, the mariners can easily obtain the optimistic trim by the formula or the trimming-speed curve on the picture under designated loading condition. Meanwhile, the optimistic trim are obtained under more loading condition if sea trial would be carried out under various loading condition .The trimming-draft-speed curve surface is shown as figure 3.

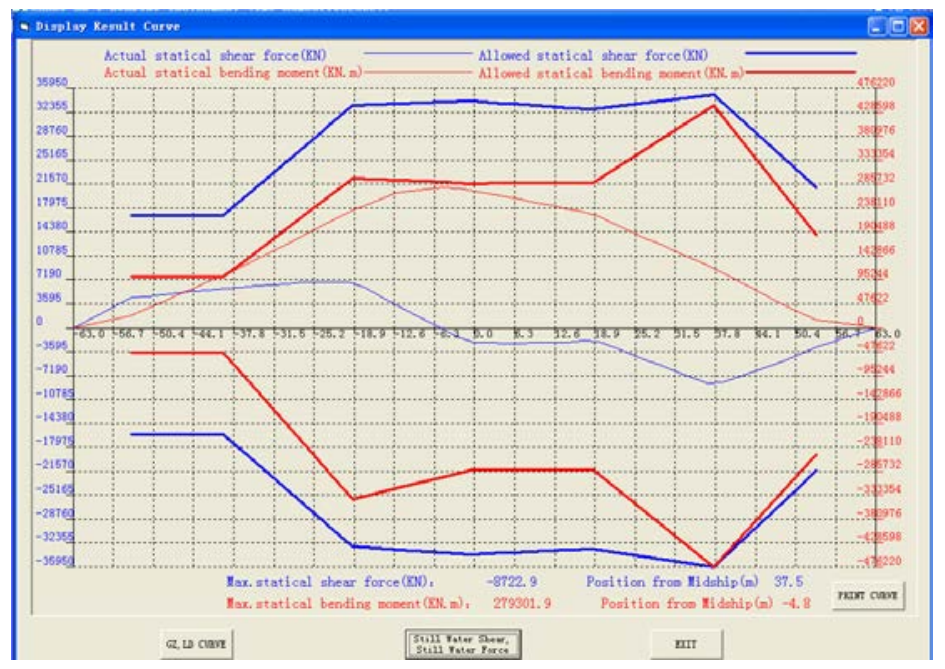

Fig.2 Shear force and bending moment interface

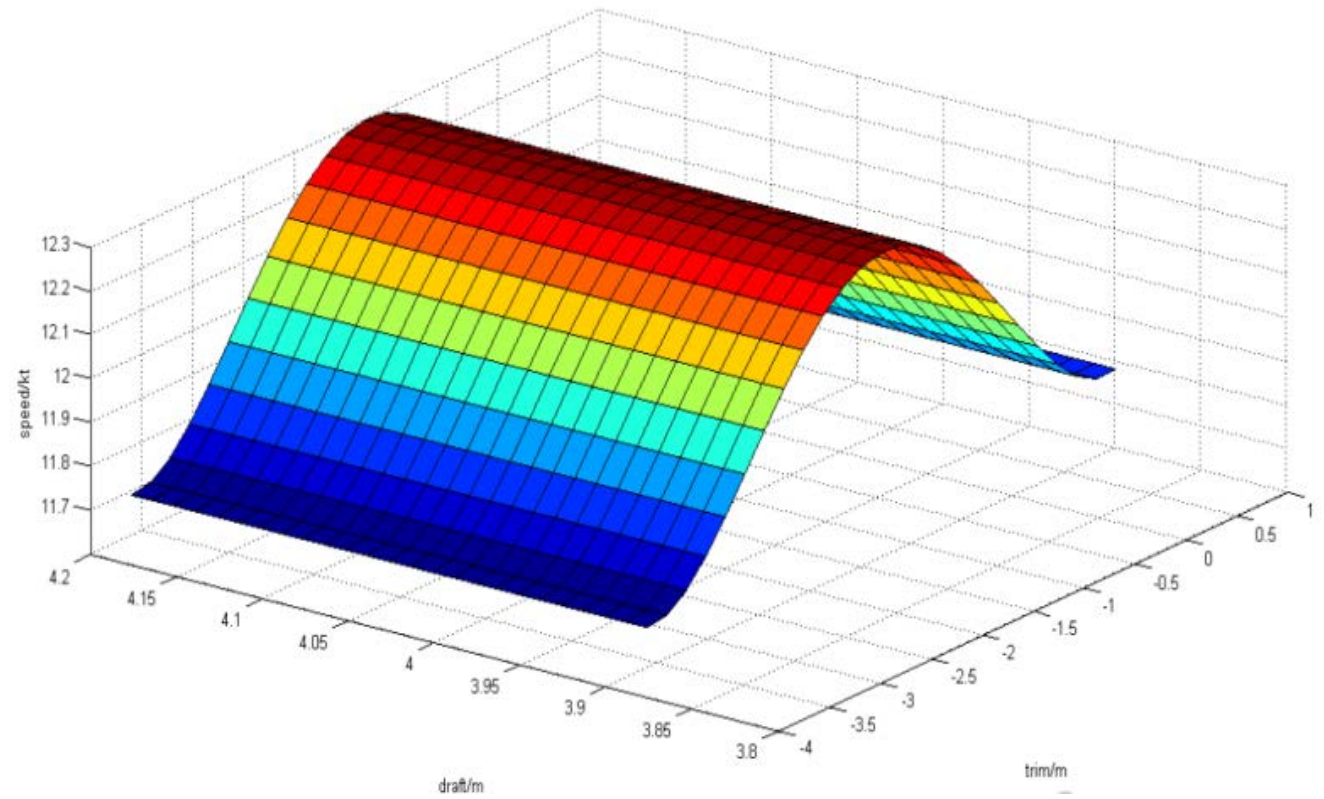

Fig.3 Trimming-draft-speed curve surface

\section{Conclusions}

Actually, the dynamic trimming optimization of ship is a kind of new method which change the traditional shipping view that the ship's trimming are adjusted by experiences which will be abandoned in the ships operation management. Nowadays, the study of trimming theories and the quantities of experiment data are available to persuade the mariners to use the dynamic trimming optimization,otherwise the way of reducing the energy consumption and air exhausting with suitable trim by head is hardly extensive usage because the progress will be in a dilemma by traditional theories.

The sea trial vessel of the M.T. CA which the mariners ' experience operation are loading 3100 tons ballast water, trim $-2 \mathrm{~m}$, trial speed $12.2 \mathrm{kn}$. comparing with dynamic trim-1m and trial speed $12.33 \mathrm{kn}$,the speed is increased by $1.1 \%$,so that the energy is reduced by $1.1 \%$. This sea trail belong to 
routine job and easy to operate for mariners, which can be carried out during the exchange operation of ballast water.And the Loading computer is normally used to calculate and monitor the data of each ballast tank and ship condition.Comparing with the traditional CFD method, It could reduce the cost .Notwithstanding ship model method can simulate all ship loading conditions, there are lot of ship still in single condition so that is no necessary to obtain all parameter at all loading condition. For example, the ballast data of a light displacement tanker is fixed.So that the applicability of this simple method is good for ship operations, which can provide the reference of the optimistic trimming calculation for mariners.But the method of optimistic trimming by adjusting the ballast water is not available at full displacement due to overloading problems. Then the optimistic trimming need to be continuously summarized by mariners during ship operational management.

Though the navigation environment and international shipping markets are updating all the time, the dynamic trim optimization technique is still a simple method to operate and reduce the cost.With the development of ship-shore internet,the ship basic maneuvering parameter will be obtained directly by big data analysis which is more effective than the CFD and ship model method. Therefore, this paper also provides a new research way to analyze the ship optimistic maneuvering by the big data analysis when ship-shore internet are completed economically.

\section{Acknowledgements}

Research presented in this paper was sponsored by the Shandong Jiaotong University Foundation.

\section{References}

[1] Hansen H., Hochkirch K. (2013), Lean ECO - Assistant Production for Trimming Optimisation[C], 11th International Conference on Computer and IT Applications in the Maritime Industries, COMPIT 2013, Cortona, Italy.

[2] Hochkirch K., Mallol B. (2013), On the Importance of Full - Scale CFD Simulations for Ships[C], 11th International Conference on Computer and IT Applications in the Maritime Industries, COMPIT 2013, Cortona, Italy.

[3] Wang Wei.Trimming optimization to decline to ship consume and economy energy [J]. China water transport.2013.13(12):7-11.(in Chinese)

[4] Qiu Binbin.Ship trimming optimization[J].China ship survey. 2014.2. pp:70-74.(in Chinese)

[5] M.Reichel,A.Minchev,N.L.Larsen.Trimming optimisation -Theory and Practice[J].The International Journal on Marine Navigation and Safety of Sea Transportation.2014.12(8):387-392. 